\title{
Is prehospital use of active external warming dangerous for patients with accidental hypothermia: a systematic review
}

Sigurd Mydske $\mathrm{e}^{1,2^{*}}$ (i) and Øyvind Thomassen ${ }^{1,2,3}$

\begin{abstract}
Background: Optimal prehospital management and treatment of patients with accidental hypothermia is a matter of frequent debate, with controversies usually revolving around the subject of rewarming. The rule of thumb in primary emergency care and first aid for patients with accidental hypothermia has traditionally been to be refrain from prehospital active rewarming and to focus on preventing further heat loss. The potential danger of active external rewarming in a prehospital setting has previously been generally accepted among the emergency medicine community based on a fear of potential complications, such as "afterdrop", "rewarming syndrome", and "circum-rescue collapse". This has led to a reluctancy from health care providers to provide patients with active external rewarming outside the hospital. Different theories and hypotheses exist for these physiological phenomena, but the scientific evidence is limited. The research question is whether the prehospital use of active external rewarming is dangerous for patients with accidental hypothermia. This systematic review intends to describe the acute unfavourable adverse effects of active external rewarming on patients with accidental hypothermia.

Methods: A literature search of the Cochrane Library, MEDLINE, EMBASE, the Cumulative Index to Nursing and Allied Health Literature (CINAHL], and SveMed+ was carried out, and all articles were screened for eligibility. All article formats were included.

Results: Two thousand three hundred two articles were screened, and eight articles met our search criteria. Three articles were case reports or case series, one was a prospective study, two were retrospective studies, one article was a literature review, and one article was a war report from the Napoleonic Wars.

Conclusions: One of the main findings in this article was the poor scientific quality and the low number of articles meeting our inclusion criteria. When conducting this review, we found no scientific evidence of acceptable quality to prove that the use of active external rewarming is dangerous for patients with accidental hypothermia in a prehospital setting. We found several articles claiming that active external rewarming is dangerous, but most of them do not cite references or provide evidence.
\end{abstract}

Keywords: Accidental hypothermia, Active external rewarming, Prehospital, Emergency medicine, Systematic review

\footnotetext{
* Correspondence: sigurd.mydske@gmail.com

'Department of Anaesthesia and Intensive Care, Haukeland University

Hospital, Bergen, Norway

${ }^{2}$ Mountain Medicine Research Group, University of Bergen, Bergen, Norway

Full list of author information is available at the end of the article
} 


\section{Background}

Accidental hypothermia $(\mathrm{AH}]$ is defined as an involuntary drop in core body temperature to below $35^{\circ} \mathrm{C}$ [1]. The golden standard for rewarming in severe hypothermia is the use of extracorporeal techniques, but this technology is rarely accessible outside of major trauma centres. Therefore, prehospital warming modalities are usually limited to passive external rewarming (PER) and active external rewarming (AER) techniques [2].

Hypothermia has a multitude of complications, including cardiac arrhythmia, pulmonary oedema, renal failure, hypotension, coagulopathy, and neurological pathology [1, 3-5]. Distinguishing between complications from active rewarming and the pathophysiological response to rewarming may sometimes be impossible. Hypothermia is an independent risk factor for increased mortality and morbidity in injured patients, and is also potentially fatal without any accompanying conditions $[6,7]$. Given the serious consequences of being cold, any advice to abstain from warming patients should be well-documented, and the adverse effects of warming should outweigh those of being hypothermic.

The aim of this review is to identify and describe all scientific reports describing clinical complications or adverse effects occurring during rewarming of patients with AH using AER. We did not aim to report the effect of AER or the consequences of AER on core temperature afterdrop. Neither did we intend to speculate about the danger of afterdrop in patients with $\mathrm{AH}$, nor to describe clinical complications of hypothermia, only the complications directly related to the use of AER. In this review, we define "complication" as any clinical haemodynamic or respiratory deterioration occurring $\leq 1 \mathrm{~h}$ after the application of AER. We decided to use this timeframe because the suspected dangerous aetiologies (i.e., vasodilatation or increased afterdrop) should present with symptoms within $1 \mathrm{~h}$ if they have any clinical consequences.

Therefore, asymptomatic increased afterdrop was not considered a complication. Late adverse effects of hypothermia also were not considered complications, as they may be considered consequences of hypothermia itself and not necessarily an effect of AER.

\section{Methods}

The research protocol, including the search strategies, is available online [8]. We used the PRISMA checklist as a framework for conducting this review [9].

\section{Search strategies}

A literature search of the Cochrane Library, MEDLINE, EMBASE, the Cumulative Index to Nursing and Allied Health Literature (CINAHL), and SveMed+ was carried out on 3 August 2018. An update search was conducted on 25 June 2020.

We used subject headings when applicable, with the addition of free-text search terms and terminology to complete the search strategy. We decided to be very liberal with both our search criteria and in the selection of included article formats. This was necessary in order to obtain all of the necessary articles for the review because of the inconsistent use of terminology in scientific literature.

\section{Inclusion and exclusion criteria}

We used the PICO framework for focused clinical questions [10].

\section{Population: Patients with AH.}

Intervention: Patients with $\mathrm{AH}$ who received AER, using non-invasive or minimally invasive techniques only.

Comparison: Ideally, studies in which the intervention was compared to a control group. Outcome: Unfavourable outcome including rewarming syndrome, rewarming shock, rescue collapse, or any other negative physiological response to the intervention (i.e., cardiac arrhythmia, pulmonary oedema, renal failure, hypotension, coagulopathy, neurological pathology, or other complication).

Our search was not limited with regard to publication date, as the origin of the hypothesis regarding the resistance to AER in the prehospital setting has been relevant for centuries. There was no restriction on patient age, but we chose to exclude studies concerning hypothermia in preterm neonates, as these articles describe an intrahospital setting. We excluded articles regarding therapeutic hypothermia and invasive treatment. We also excluded animal studies.

For obvious ethical reasons, randomized controlled trials are lacking. Therefore, current guidelines and practice rely heavily on observations, case reports, and the clinical experience. Consequently, all such articles must be eligible for review and critical consideration. All languages were considered and, if necessary, translated.

\section{Study selection}

After the searches were completed, the authors (SM and OT) conducted a double-blind title screening of $10 \%$ of the articles using Rayyan QCRI Systematic Review software (Qatar Computing Research Institute, Hamad Bin Khalifa University) [11] in order to ensure mutual understanding regarding the studies eligible for inclusion. From this, we calculated a Cohens Kappa Coefficient ( ) of 0.78 which indicate a moderate-to-strong interrater reliability [12]. We deemed this acceptable due to the fact that the reviewer who would be conducting the initial title-screening (SM) consistently included studies the second reviewer (OT) chose to exclude. Therefore, there 
would be minimal risk of falsely excluding relevant articles.

SM then screened the rest of the titles and excluded those that were obviously ineligible. After this, both reviewers screened the abstracts to determine eligibility using Rayyan QCRI in a double-blind manner. Finally, we conducted a double-blind full-text selection. If there was a discrepancy between the reviewers, the article was included in the next selection step (Fig. 1).

\section{Data synthesis and stratification}

Due to the lack of randomized controlled trials and other high-quality scientific literature regarding this subject, a large number of article formats were eligible for inclusion.

\section{Risk of bias assessment}

Evaluating the risk of bias proved to be difficult given the variety of included studies. Risk of bias was assessed using the STROBE checklist [13] for the observational studies and the CARE checklist was applied to the case reports [14]. We were unable to find applicable validated tools for the remaining article formats.

\section{Results}

Eight articles [15-22] met our inclusion criteria for this review: Three were case reports or case series, one was a prospective study, two were retrospective studies, one article was a literature review, and one article was a war report from the Napoleonic Wars (Table 1).

\section{Complications following AER}

The most common complications reported from AER were a drop in blood pressure [15-17], dangerous cardiac arrythmias $[15,16]$ and reduced level of consciousness $[15,17]$, sometimes resulting in death. Four studies reported an increased mortality rate in patients receiving AER compared to patients receiving PER [18-21].

\section{Modality of AER with unfavourable outcome}

In two of the studies reporting unfavourable outcome from AER an electric blanket was used [15, 17]. One study reports hot water immersion [20] and one reports the use of forced air warming. Three of our studies does not explicitly report the modality of AER used in the reported cases [18, 19, 21].

\section{Main findings}

The article from the Napoleonic wars [22] concludes that a rapid rewarming is dangerous, and one should adopt a slower approach to rewarming, which is partially supported by Fruehan [19]. Gregory argues that a passive rewarming approach seems to be safer [21]. In the prospective study by Duguid, she reports that a total of 6 patients was treated with AER, all of whom promptly died [18]. Treatment with AER was deemed dangerous and was discontinued. Coopwood and Strapazzon recommends the use of AER but advises caution during treatment due to risk of potentially fatal complications $[15,16]$.

\section{Study quality}

As presented in the table, the overall quality of the studies included in this review was low. The lack of highquality research is due, at least in part, to the obvious ethical and practical challenges that make it difficult to conduct proper clinical studies on this subject.

The included cohort studies are not detailed enough to attribute the less favourable outcome of the patients in the AER group to AER itself; crucial information is missing to draw that conclusion [18-20]. However, these articles are frequently cited as the source of the dangers of AER in the medical literature. The studies are very old and have crucial methodical flaws, as indicated by their low STROBE score.

The case reports also have methodical weaknesses. The report from Emslie-Smith is a case series, but only one of the cases met our inclusion criteria [17]. The report from Strapazzon is of good quality, but it is difficult to assess whether the complications occur because of the hypothermia or the AER [16].

\section{Discussion}

\section{Complications following AER and pathophysiology}

Several different physiological theories have been proposed to explain why AER is dangerous, and most of them argue that AER affects afterdrop, a thermodynamic phenomenon. As dictated by the second law of thermodynamics, heat will flow from hot areas to cold areas [23]. In a patient with rapid onset $\mathrm{AH}$, a significant thermal gradient is present between the core and the skin and subcutaneous tissues [24]. As the patient is removed from the cold environment, the thermal energy of the body will seek equilibrium. Heat will travel from the relatively warm core out to the colder, peripheral areas of the body, which results in a drop in the core temperature $[25,26]$.

A number of theories advocate the physiological dangers of AER, and the most prevalent theory argues that AER will accelerate afterdrop by alleviating peripheral vasoconstriction. Some scientists argue that the flow of blood from the relatively warm core and out through the colder peripheral tissues will increase. They believe this relatively cold blood will return from the extremities and cool the core at a faster rate, and a thermodynamic equilibrium will be instated more rapidly than without the circulatory (convective) component [26-28].

Given that the patient is properly isolated and removed from the cold environment, the total thermal energy will not decrease, and the nadir temperature will 


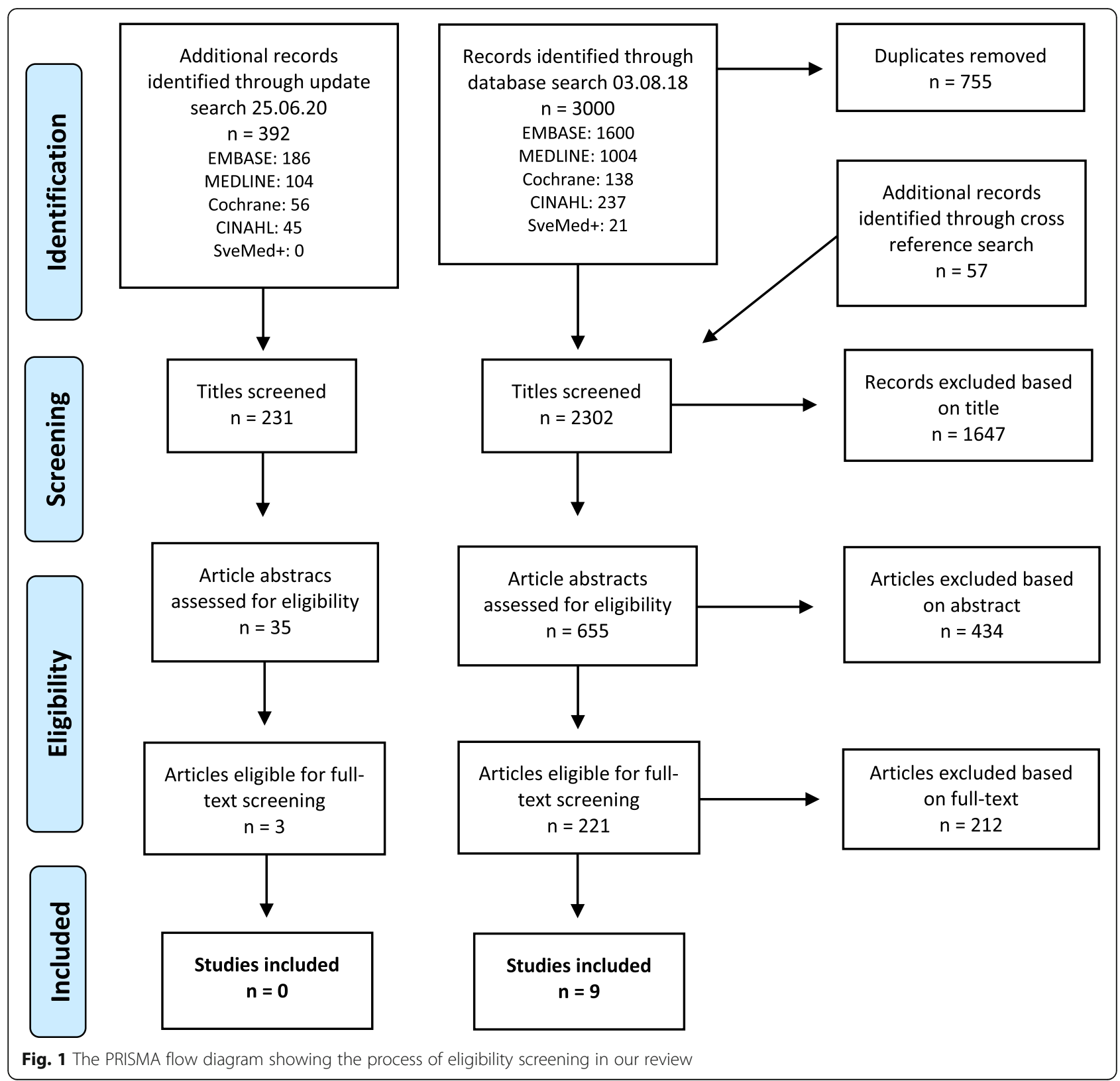

not be lower if thermal energy is supplied in the form of AER than with passive insulation alone [27]. Therefore, if this theory that AER is dangerous for patients with $\mathrm{AH}$ is true, it has to be due to the acceleration of the afterdrop and not an increase of the afterdrop. Both a convective and conductive mechanism is considered relevant, but the exact mechanism is not yet completely understood $[27,29]$.

\section{Main findings}

Ever since the Napoleonic Wars there has been significant controversy regarding AER, with several authors discouraging this practice. Lankford wrote a very interesting article on the history of cold-related injuries [30], and James Currie described the phenomenon of afterdrop for the first time [31]. In more recent history, the infamous Dachau experiments conducted by Nazi doctor Sigmund Rascher during the second world war formed the basis for a new understanding of immersion hypothermia. The report of US Major Leo Alexander contained and preserved the results from these atrocities [32]. However, the results and conclusions drawn from these experiments are heavily flawed. A review of the Nazi experiments revealed "critical shortcomings in scientific content and credibility. The project was conducted without an orderly experimental protocol, with inadequate methods, and an erratic execution. The report is riddled with inconsistencies. There is also evidence of 
Table 1 A summary of the relevant findings in the selected articles included in our review

\begin{tabular}{|c|c|c|c|c|c|c|}
\hline Article ID & Aetiology & Temp. & Case description & AER Intervention & Complication & $\begin{array}{l}\text { Quality } \\
\text { score }\end{array}$ \\
\hline $\begin{array}{l}\text { Coopwood } \\
\text { et al. } 1974 \\
{[15]}\end{array}$ & $\begin{array}{l}\text { Outdoor } \\
\text { exposure, } \\
\text { overnight }\end{array}$ & $25^{\circ} \mathrm{C}$, rec & $\begin{array}{l}\text { Male, } 70 \text { y; responsive } \\
\text { to pain, unobtainable } \\
\text { BP }\end{array}$ & Electric blanket & $\begin{array}{l}\text { Initial increase in } B P \text { and } T_{\text {rec }} \text { then sudden } \\
\text { drop in } T_{\text {rec }} \text { and } B P->V F->+\end{array}$ & $\begin{array}{l}17 / 30 \\
\text { CARE }\end{array}$ \\
\hline $\begin{array}{l}\text { Strapazzon } \\
\text { et al. } 2012 \\
\text { [16] }\end{array}$ & $\begin{array}{l}\text { Avalanche burial, } \\
2 \mathrm{~h}\end{array}$ & $\begin{array}{l}25^{\circ} \mathrm{C} \\
\text { tymp }\end{array}$ & $\begin{array}{l}\text { Male, } 42 \text { y; GCS } 10 \text {, } \\
\text { breathing, palpable } \\
\text { radial }\end{array}$ & Forced air warming & $\begin{array}{l}\text { Atrial fibrillation Pulmonary oedema } \\
\text { Hypotension Hypoglycaemia }\end{array}$ & $\begin{array}{l}21 / 30 \\
\text { CARE }\end{array}$ \\
\hline $\begin{array}{l}\text { Emslie-Smith } \\
\text { et al. } 1958 \\
{[17]}\end{array}$ & $\begin{array}{l}\text { Outdoor } \\
\text { exposure, } \\
\text { unknown } \\
\text { duration }\end{array}$ & $33^{\circ} \mathrm{C}$, rec & $\begin{array}{l}\text { Female, } 64 \text { y; stupor, } \\
\text { breathing, } \\
\text { hypothyroidism }\end{array}$ & Electric blanket & $\begin{array}{l}\text { Coma, hypotension Bronchopneumonia } \\
\text { Death }\end{array}$ & $\begin{array}{l}14 / 30 \\
\text { CARE }\end{array}$ \\
\hline Article ID & Mean age & $\begin{array}{l}\text { Mean } \\
\text { temp }\end{array}$ & AER modality & $\begin{array}{l}\text { Number of } \\
\text { patients } \\
\text { AER (Mortality in } \\
\% \text { ) }\end{array}$ & $\begin{array}{l}\text { Number of patients PER } \\
\text { (Mortality in \%) }\end{array}$ & $\begin{array}{l}\text { Quality } \\
\text { score }\end{array}$ \\
\hline $\begin{array}{l}\text { Duguid et al. } \\
1961[18]\end{array}$ & 75.3 years & $\begin{array}{l}26.5^{\circ} \mathrm{C} \\
\text { rec }\end{array}$ & Not specified & $6(100 \%)$ & 17 (58.8\%) & $\begin{array}{l}8 / 22 \\
\text { STROBE }\end{array}$ \\
\hline Article ID & $\begin{array}{l}\text { Number of } \\
\text { subjects } \\
\text { (\# treated with } \\
\text { AER) }\end{array}$ & Temp & AER Modality & $\begin{array}{l}\text { AER mortality } \\
\text { (PER Mortality) }\end{array}$ & Comments & $\begin{array}{l}\text { Quality } \\
\text { score }\end{array}$ \\
\hline $\begin{array}{l}\text { Fruehan, } 1960 \\
\text { [19] }\end{array}$ & $8(4)$ & $\begin{array}{l}\text { Mean: } \\
24.4^{\circ} \mathrm{C} \\
\operatorname{rec}^{\mathrm{a}}\end{array}$ & Not explicitly stated & $\begin{array}{l}100 \% \\
(75 \%)\end{array}$ & $\begin{array}{l}4 \text { pt. treated with some form of AER, all died; } \\
4 \text { pt. treated with PER, } 1 \text { survived }\end{array}$ & $\begin{array}{l}12 / 22 \\
\text { STROBE }\end{array}$ \\
\hline $\begin{array}{l}\text { O'Keeffe } 1973 \\
\text { [20] }\end{array}$ & $62(1)$ & $\begin{array}{l}\text { Below } \\
30^{\circ} \mathrm{C}\end{array}$ & Immersion in hot bath & $\begin{array}{l}100 \% \\
(9.8 \%)\end{array}$ & $\begin{array}{l}1 \text { pt. treated with rapid rewarming by } \\
\text { immersion, cardiac arrest immediately after } \\
\text { rewarming }\end{array}$ & $\begin{array}{l}13 / 22 \\
\text { STORBE }\end{array}$ \\
\hline Article ID & $\begin{array}{l}\text { Timespan of } \\
\text { data collection }\end{array}$ & $\begin{array}{l}\text { Overall } \\
\text { mortality }\end{array}$ & $\begin{array}{l}\text { Number of cases } \\
\text { (AER, PER, Internal) }\end{array}$ & $\begin{array}{l}\text { Mortality of } \\
\text { patients treated } \\
\text { with AER }\end{array}$ & Mortality of patients treated with PER & $\begin{array}{l}\text { Quality } \\
\text { score }\end{array}$ \\
\hline $\begin{array}{l}\text { Gregory et al. } \\
1973 \text { [21] }\end{array}$ & 1951-1972 & $48.8 \%$ & $\begin{array}{l}201 \\
(73,121,7)\end{array}$ & $60.3 \%$ & $44.6 \%$ & - \\
\hline Article ID & \multicolumn{6}{|l|}{ Description } \\
\hline $\begin{array}{l}\text { Moricheau- } \\
\text { Beaupré, } 1826 \\
{[22]}\end{array}$ & \multicolumn{6}{|c|}{$\begin{array}{l}\text { The writings of Napoleon's regimental surgeon from the Russian campaign in 1812: } \\
\text { "The like holds of general as of local asphyxia; we must not, in avoiding the danger from cold, transport the body into a heated } \\
\text { place, or immediately apply to it warm substances; too strong reaction might exhaust the remaining vitality; the dilatation of the } \\
\text { tissues and rapid expansion of the forces towards the surface, owing to sudden transition from cold and condensed to warm and } \\
\text { rarefied air, causing shooting pains, dyspnoea, suffocation, and death." }\end{array}$} \\
\hline
\end{tabular}

${ }^{\mathrm{a}}$ Endobronchial in one case

data falsification and suggestions of fabrication. Many conclusions are not supported by the facts presented" [33]. Despite the overwhelming criticism of the Dachau experiments, it may seem as though some of the conclusions survived. The Nazi scientists observed a continuous drop in core temperature, and they postulated that this drop in temperature may be responsible for dangerous cardiac arrhythmias.

Since then, many scientific papers have warned about the danger of AER, most of them without citing references [34-45]. This may indicate that this theory was sufficiently established as an undisputed truth, even though no scientific evidence supports this.

The articles included in this review, and others that did not meet our specific criteria, report a fairly high mortality rate in patients with $\mathrm{AH}$. It may seem as though the vast majority of deaths occur long after treatment with AER is initiated, or even after the patient is successfully rewarmed $[4,46]$. We think that, if the hypothesis of a sudden cardiovascular collapse after AER is true, then the complications should occur fairly soon after the treatment is initiated. It is unreasonable to attribute all of the late deaths from hypothermia to the use of $\mathrm{AER}$, as these deaths are more likely to be a consequence of other pathophysiological mechanisms.

Despite the controversies from old studies, AER is being used in many hospitals today. The fact that we have found only one case published over the last 30 years presenting potential harm from AER would suggest a low risk of complications. In fact, there are numerous articles reporting successful rewarming using AER [47-49], and the general consensus among experts seems to be shifting [1, 2, 50-52]. 
This review does not mean to make a conclusion on whether it is safe to use AER in patients with AH. The aim is limited to describing published studies on severe haemodynamic or respiratory complications caused directly by the use of AER. One of the main findings of this review was the low number of articles, and the low quality of those that were found. Relevant cases may not be published because the authors do not believe that it will contribute anything new. Of course, it may also be because the use of AER is not as dangerous as previously perceived.

One specific subgroup may have good reason to be cautious with AER, chronic AH [26, 53]. Chronic hypothermia is most prevalent in the elderly population and can lead to a variety of pathophysiological changes. Shifts in fluid and electrolytes occur that are not immediately reversible and may require more controlled and steady correction [51, 54]. The cold diuresis will have had time to manifest for a prolonged period of time, and the patient may require fluid replacement therapy during rewarming.

\section{Limitations}

\section{Study quality}

A systematic review is considered to be evidence-based science of high quality, summarizing data from multiple randomized controlled trials to synthesize all available knowledge on a specific subject. This review consists mostly of case reports, case series, and small clinical trials with low scientific value. Even though this is a systematic review of the available scientific literature, the quality of the scientific evidence is not as convincing as other systematic reviews. Therefore, the conclusions drawn from this review and the clinical implications must be cautious and reserved.

\section{Search strategies}

We chose to exclude all studies involving invasive or extracorporeal techniques of rewarming in their title. However, it is obviously possible that some of the studies advocating the use of invasive warming techniques contain examples of why the use of external warming measures might be dangerous.

\section{Study selection process}

During the initial screening for this study, 2200 articles were excluded. There is always a risk that some article titles did not immediately catch our attention and were falsely excluded. Also, 13 articles meeting our search criteria were unobtainable.

\section{Inclusion and exclusion criteria}

We chose our inclusion criteria based on what kind of literature we thought would yield the most accurate answer to our research question. However, there may be, for example, animal or laboratory studies available that would have been of interest for this review.

\section{Conclusion}

When conducting this review, we found no scientific evidence of acceptable quality to prove that the use of AER is dangerous for patients with $\mathrm{AH}$ in a prehospital setting.

We found several articles saying that AER is dangerous, but most of them do not cite references or provide evidence. It has become an undisputed fact without ever being proven to be true.

Several articles argue that the use of AER is safe and effective. These recommendations are not based on scientific evidence, but on the consensus of expert groups and commissions. This review can hopefully be a contribution to this growing body of evidence.

\section{Definitions}

In the preparation phase of this systematic review, we found some inconsistencies in the literature regarding some key concepts [55]. Therefore, we deemed it necessary to clarify some of these terms in order to achieve a common understanding of the results found in this review.

\section{Afterdrop}

Afterdrop is exclusively a thermodynamic concept. It is defined as a continued decrease in the core temperature after extraction from the cold environment [56, 57]. The term afterdrop includes both the circulatory component (convective) and the direct conduction of heat in tissue (conductive] [27].

\section{Rewarming syndrome}

Rewarming syndrome is the combined result of all physiological and pathophysiological effects occurring during rewarming. The observed effects of rewarming syndrome consist of a rapid decrease in cardiac output and arterial blood pressure [58-60].

\section{Rewarming shock}

Rewarming shock is a state of circulatory shock following severe rewarming syndrome.

\section{Circum-rescue collapse}

Circum-rescue collapse is a pathophysiological phenomenon consisting of a sudden collapse of arterial blood pressure immediately prior to, during, or shortly after rescue from a hypothermic environment [56]. The term is frequently used in relation to extraction from water immersion. 


\section{Active warming}

Active warming is when heat is supplied to the patient from an exogenous heat source [61].

\section{Passive warming}

Passive rewarming is when the patient is insulated from the environment, allowing endogenous heat production to increase the core temperature $[48,62]$.

\section{External/non-invasive}

External heating is when heat is applied to the skin, depending on convective or conductive heat transfer to increase the core temperature [61]. Examples of this modality is electrical blankets, forced air blankets, hot water immersion, heat packs, heated mattress, or hot water bottles [3, 47].

\section{Extracorporeal rewarming}

Invasive techniques in which the patient's blood is circulated out of the body and rewarmed by a machine before being reinfused back into the patient's own circulation $[2,63]$. This can be accomplished by extracorporeal membrane oxygenation (ECMO), cardiopulmonary bypass, or haemodialysis.

\section{Internal/invasive rewarming}

Internal rewarming is when heat is applied directly to the patient's core [51]. Examples of this is heated intravenous infusions; peritoneal-, gastric-, colonic-, or pleural lavage; or inhalation of heated air [51].

\section{Abbreviations}

$\mathrm{AH}$ : Accidental hypothermia; AER: Active external rewarming; PER: Passive external rewarming

\section{Acknowledgements}

We would like to thank the University Library in Bergen, particularly Ms. Regina Küfner Lein, for their contributions to this review. We would also like to thank Prof. Guttorm Brattebø, MD, PhD, for valuable feedback during the review process.

\section{Authors' contributions}

SM and OT both contributed to screening the articles for eligibility. SM is the main author of this review article. The author(s) read and approved the final manuscript.

\section{Funding}

Not applicable.

\section{Availability of data and materials}

Our research protocol, including detailed search strategies, is available online from the PROSPERO website: https://www.crd.york.ac.uk/PROSPERO/display_ record.php?RecordID $=107137$

\section{Ethics approval and consent to participate}

Not applicable.

\section{Consent for publication}

Not applicable.

\section{Competing interests}

The authors declare that they have no competing interests.

\section{Author details}

${ }^{1}$ Department of Anaesthesia and Intensive Care, Haukeland University Hospital, Bergen, Norway. ${ }^{2}$ Mountain Medicine Research Group, University of Bergen, Bergen, Norway. ${ }^{3}$ Department of Research and Development, Norwegian Air Ambulance Foundation, Oslo, Norway.

Received: 9 March 2020 Accepted: 29 July 2020

Published online: 10 August 2020

References

1. Haverkamp FJC, Giesbrecht GG, Tan ECTH. The prehospital management of hypothermia - an up-to-date overview. Injury. 2018;49(2):149-64.

2. Paal P, Gordon L, Strapazzon G, Brodmann Maeder M, Putzer G, Walpoth B, et al. Accidental hypothermia-an update : the content of this review is endorsed by the International Commission for Mountain Emergency Medicine (ICAR MEDCOM). Scand J Trauma Resusc Emerg Med. 2016;24(1):111.

3. Van der Ploeg GJ, Goslings JC, Walpoth BH, Bierens JJLM. Accidental hypothermia: rewarming treatments, complications and outcomes from one university medical centre. Resuscitation. 2010;81(11):1550-5.

4. Morales CF, Strollo PJ. Noncardiogenic pulmonary edema associated with accidental hypothermia. Chest. 1993;103(3):971-3.

5. Yoon HJ, Kim MC, Park JW, Yang MA, Lee CB, Sun IO, et al. Hypothermiainduced acute kidney injury in an elderly patient. Kor J Intern Med. 2014; 29(1):111-5.

6. Ireland S, Endacott R, Cameron P, Fitzgerald M, Paul E. The incidence and significance of accidental hypothermia in major trauma--a prospective observational study. Resuscitation. 82(3):300-6.

7. Vardon F, Mrozek S, Geeraerts T, Fourcade O. Accidental hypothermia in severe trauma. Anaesth Crit Care Pain Med. 35(5):355-61.

8. Mydske $\mathrm{S}$, Thomassen $\mathrm{O}$. Is the prehospital use of active warming dangerous for patients with accidental hypothermia?. PROSPERO; 2019 [CRD42019107137]. Available from: https://www.crd.york.ac.uk/prospero/ display record.php?ID=CRD42019107137.

9. Moher D, Liberati A, Tetzlaff J, Altman DG, The PG. Preferred reporting items for systematic reviews and meta-analyses: The PRISMA statement. PLoS Med. 2009;6(7):e1000097

10. Higgins JPT TJ, Chandler J, Cumpston M, Li T, Page MJ, Welch VA. Cochrane handbook for systematic reviews of interventions version 6.0 (updated July 2019): Cochrane; 2019 [Available from: www.training.cochrane.org/ handbook.

11. Ouzzani M, Hammady H, Fedorowicz Z, Elmagarmid A. Rayyan-a web and mobile app for systematic reviews. Syst Rev. 2016;5(1):210.

12. McHugh ML. Interrater reliability: the kappa statistic. Biochem Med. 2012; 22(3):276-82.

13. Cuschieri S. The STROBE quidelines. Saudi J Anaesth. 2019;13(Suppl 1):S31-S4

14. Gagnier JJ, Kienle G, Altman DG, Moher D, Sox H, Riley D, et al. The CARE guidelines: consensus-based clinical case reporting guideline development. J Med Case Rep. 2013;7(1):223.

15. Coopwood TB, Kennedy JH. Accidental hypothermia. Cardiovasc Res Cent Bull. 1974;12(4):104-11.

16. Strapazzon G, Nardin M, Zanon P, Kaufmann M, Kritzinger M, Brugger $H$. Respiratory failure and spontaneous hypoglycemia during noninvasive rewarming from 24.7 degreeC (76.5degreeF) core body temperature after prolonged avalanche burial. Ann Emerg Med. 2012:60(2):193-6.

17. Emslie-Smith D. Accidental hypothermia a common condition with a pathognomonic electrocardiogram. Lancet. 1958;272(7045):492-5.

18. Duguid H, Simpson RG, Stowers JM. Accidental hypothermia. Lancet. 1961; 278(7214):1213-9.

19. Fruehan AE. Accidental hypothermia: report of eight cases of subnormal body temperature due to exposure. Arch Intern Med. 1960;106(2):218-29.

20. O'Keeffe KM. Accidental hypothermia: a review of 62 cases. J Am Coll Emerg Phys. 1977;6(11):491-6.

21. Gregory RT, Doolittle WM. Accidental hypothermia. Part II: clinical implications of experimental studies. Alaska Med. 1973;15(2):48-52.

22. Moricheau-Beaupré PJ. In: Stewart M, editor. A treatise on the effects and properties of cold, with a sketch, historical and medical, of the Russian campaign. MacLachlan \& Stewart: Edinburgh; 1826.

23. Clausius R. In: Hirst A, editor. The mechanical theory of heat - with its applications to the steam engine and to physical properties of bodies. London: John Van Voorst; 1867 
24. Harnett RM, Pruitt JR, Sias FR. A review of the literature concerning resuscitation from hypothermia: Part l--the problem and general approaches. Aviat Space Environ Med. 1983;54(5):425-34.

25. Lloyd EL. Accidental hypothermia. Resuscitation. 1996;32(2):111-24.

26. Hayward JS, Eckerson JD, Kemna D. Thermal and cardiovascular changes during three methods of resuscitation from mild hypothermia. Resuscitation. 1984;11(1):21-33.

27. Romet TT. Mechanism of afterdrop after cold water immersion. J Appl Physiol. 1988;65(4):1535-8.

28. Giesbrecht GG, Bristow GK. A second postcooling afterdrop: more evidence for a convective mechanism. J Appl Physiol. 1992;73(4):1253-8.

29. Zafren K, Giesbrecht GG, Danzl DF, Brugger H, Sagalyn EB, Walpoth B, et al. Wilderness medical society practice guidelines for the out-of-hospital evaluation and treatment of accidental hypothermia: 2014 update. Wilderness Environ Med. 2014;25(4, Supplement):S66-85.

30. Lankford HV. Dull brains and frozen feet: a historical essay on cold. Wilderness Environ Med. 2016;27(4):526-32.

31. Currie J. Medical reports: on the effects of water, cold and warm, as a remedy in fever and other diseases, whether applied to the surface of the body, or used internally: T. Cadell; 1805.

32. Alexander $\mathrm{L}$. The treatment of shock from prolonged exposure to cold, especially in water. 1945. Contract No.: Report No 250.

33. Berger RL. Nazi science - The Dachau hypothermia experiments. N Engl J Med. 1990;322(20):1435-40

34. Le Conte P, Baron D. Accidental hypothermia. Rev Prat. 1998;48(3):343-5

35. Jessen K, Hagelsten JO, Graae J. Description of the patho physiology of acute accidental hypothermia (Danish). Ugeskr Laeger. 1974;136(46):2590-5.

36. Hancock EW. Hypothermia, slow pulse, and an unusual QRS complex. Hosp Pract. 1996;31(11):25-6.

37. Stackhouse DE. Hypothermia: rewarming and therapy. Physician Assist. 1987; 11(2):37-46.

38. Jessen K. Immersion and accidental hypothermia. Acta Medica Port. 1979; $1(2): 225-37$.

39. Bracker MD. Environmental and thermal injury. Clin Sports Med. 1992;11(2): 419-36.

40. Day MP. Hypothermia: a hazard for all seasons. Nursing. 2006:36(12 Pt.1):44-7.

41. Skilbreid AK. The right way of warming is the alpha and omega in cold and frost injuries. Ugeskr Laeger. 1985;85(9):4-7.

42. Anonymous. Hypothermia. CMAJ. 1998;158(2):237.

43. Kugelberg J, Schüller H, Berg B, Kallum B. Treatment of accidental hypothermia. Scand J Thorac Cardiovasc Surg. 1967;1:142-6.

44. Editorial. Treating accidental hypothermia. Lancet. 1978;311(8066):701-2.

45. Evered A. Hypothermia: risk factors and guidelines for nursing care. Nurs Times. 2003;99(49):40-3.

46. Yates DW, Little RA. Accidental hypothermia. Resuscitation. 1979;7(1):59-67.

47. Daanen HAM, Van de Linde FJG. Comparison of four noninvasive rewarming methods for mild hypothermia. Aviat Space Environ Med. 1992; 63(12):1070-6.

48. Larach MG. Accidental hypothermia. Lancet. 1995;345(8948):493-8.

49. Light IM, Norman JN, Stoddart M. Rewarming from immersion hypothermia: reduction of afterdrop. Scott Med J. 1983;28(1):80-1.

50. Thomassen O. Guidelines for management of accidental hypothermia [Faglig retningslinje for håndtering av aksidentell hypotermi]. nakos.no: NKT; 2017.

51. Zafren K. Accidental hypothermia in adults - UpToDate.com uptodate. com2019.

52. Zafren K. Out-of-hospital evaluation and treatment of accidental hypothermia. Emerg Med Clin North Am. 2017;35(2):261-79.

53. Danzl DF, Pozos RS. Accidental hypothermia. N Engl J Med. 1994;331(26): 1756-60.

54. Giesbrecht GG. Cold stress, near drowning and accidental hypothermia: a review. Aviat Space Environ Med. 2000;71(7):733-52.

55. Giesbrecht GG, Hayward JS. Problems and complications with cold-water rescue. Wilderness Environ Med. 2006;17(1):26-30.

56. Golden FS, Hervey GR, Tipton MJ. Circum-rescue collapse: collapse, sometimes fatal, associated with rescue of immersion victims. J R Nav Med Serv. 1991;77(3):139-49.

57. Webb P. Afterdrop of body temperature during rewarming: an alternative explanation. J Appl Physiol (1985). 1986;60(2):385.

58. Lonning PE, Skulberg A, Abyholm F. Accidental hypothermia. Review of the literature. Acta Anaesthesiol Scand. 1986;30(8):601-13.
59. Tveita T. Rewarming from hypothermia. Newer aspects on the pathophysiology of rewarming shock. Int J Circumpolar Health. 2000;59(34):260-6.

60. Maclean D. In: Emslie-Smith D, editor. Accidental hypothermia. Oxford: Blackwell Scientific; 1977

61. Corneli HM. Accidental hypothermia. Pediatr Emerg Care. 2012;28(5):475-80

62. Davis PR, Byers M. Accidental hypothermia. J R Army Med Corps. 2005; 151(4):223-33.

63. Vretenar DF, Urschel JD, Parrott JCW, Unruh HW. Cardiopulmonary bypass resuscitation for accidental hypothermia. Ann Thorac Surg. 1994;58(3):895-8.

\section{Publisher's Note}

Springer Nature remains neutral with regard to jurisdictional claims in published maps and institutional affiliations.
Ready to submit your research? Choose BMC and benefit from:

- fast, convenient online submission

- thorough peer review by experienced researchers in your field

- rapid publication on acceptance

- support for research data, including large and complex data types

- gold Open Access which fosters wider collaboration and increased citations

- maximum visibility for your research: over $100 \mathrm{M}$ website views per year

At BMC, research is always in progress.

Learn more biomedcentral.com/submissions 